\title{
On the Apocalypse that No One Noticed
}

"[W] hat if they gave an apocalypse and nobody noticed?" was the question that Brooks Landon (1991, 239) proposed as the central thematic concern of the 1980s cyberpunk - a movement which today represents a landmark in the development of the science fiction genre. Diverse as they are in their focus and scope, the contributions to this issue of ELOPE, dedicated to the position and role of speculative fiction, and especially science fiction, in a world which is increasingly becoming speculative and science fictional, invariably demonstrate that an apocalypse did indeed take place and went by largely unnoticed.

From the present perspective, the cyberpunk movement is revealed as the inevitable response of science fiction (SF) - and fiction in general - to the cultural realities of the early 1980s, when the processes implicit in the development of the economy, society and culture after the Second World War culminated on the level of everyday experiential reality. These processes have been part and parcel of the globalizing tendencies of post-industrial capitalism, fuelled by the rapid growth of advertising and media industries, and facilitated by exponential development of information technologies which have provided ever more effective means for the storage, manipulation and distribution of information. The ubiquity of media that disseminate information on a global scale instigated the gradual modification of the value systems of individuals, and the formation of mass identity and mass culture.

Under the constant barrage of media-generated global trends, the notion of reality came to rely less and less on subjective, lived experience, but rather on its mediated reproductions. As these primarily serve the interests of global capitalism, the capitalist shift of production relations, in the process of which buying becomes consumption, at this point reaches its definitive stage, whereupon the representational value of products completely replaces their functional and exchange values. Products become objects of consumption which circulate as signs, creating meaning in relation to other signs. Through the act of consumption they represent - signify - the consumer, making the popular maxim "you are what you buy" acutely literal.

The processes described have gradually transformed the established concepts of reality and subject to the point where the now-transformed concept is no longer part of the same ontological order as its original counterpart. Such major alterations of the fundamental metaphysical paradigms have historically coincided with the changing of epochs, and indeed, the developments described above are invariably recognized by theoreticians in all pertinent disciplines as being inherent to the advent of the new epoch generally referred to as postmodernity. Arguably the most succinct conceptual framework - a framework which effectively incorporates all the main accents of existing theoretical discourse on postmodernity - was the one developed by Jean Baudrillard (cf. Krevel 2016, 175-76). His notions of hyperreality and the fractal subject also seem the most appropriate instruments for explaining the apocalypse Landon was referring to, as well as for assessing the impact of that apocalypse on science fiction. 
Hyperreality refers to the reality of mediated reproductions of experience, a condition that involves "substituting signs of the real for the real itself" (Baudrillard 2004, 366). Such reality is produced from "matrices, memory banks and command models - and with these it can be reproduced an indefinite number of times" (Baudrillard 2004, 366). In other words, our notions of what is real depend on data we receive through what has become - due to the digitalization of all media (from print to movies and music and film) - a single communication channel. Because all media are now encoded in the same, digital, way, we have seen an "erasing [of] the notion of the medium" (Kittler, von Mücke and Similon 1987, 102). Hence, digitally coded information transferred through this channel conditions our perception of the environment, but refers to nothing tangible, as it is an algorithm, a sign, a mere probability of a message (cf. Shannon and Weaver 1949, 3). The actual message relies on the configurations that these signs establish with other signs, meaning that what we perceive as reality is a system of more or less compatible information, against which each new piece (or cluster) of information is verified. Such reality is therefore but one of the many potential configurations of the signs that circulate the postmodern mediascape, which means that in the paradigm of the hyperreal all realities exist simultaneously as a potentiality.

Similarly, Baudrillard's fractal postmodern subject $(2011,47)$ refers to the multiplicity of selves, creatable through the consumption of available objects-turned-signs. The subject is fractal - "not at all contradictory with mass status, [...] both subdivisible to infinity and indivisible, closed on [it]self" (Baudrillard 2011, 64) - because all individuals choose from a common fund of these signs, and because these signs are coded in the same way. Consequently, such a subject is a "subject without other" (Baudrillard 2011, 64), an endless variation on the same subject, which means that the postmodern self is essentially a potential identity creatable from available signs. In the paradigm of the fractal subject, then, all identities exist at the same time as a potentiality, and what we perceive as a self is an identity variant actualized by observation.

To stir this discussion in the direction of our central concern - science fiction - let us briefly examine the framework presented in terms of the discipline that has been recognized as the scientific counterpart to the historical change of paradigm, as well as to the ontology of the new epoch: quantum physics. Complex, controversial and complicated to the point of incomprehensibility as quantum physics may be, the conceptual compatibility with postmodern metaphysics is implicit in its fundamental premise: namely that on the subatomic levels, matter and energy behave according to the principles of superposition, entanglement and the measurement problem, which cannot be accounted for by the principles of Newtonian physics. ${ }^{1}$ Perhaps the best way to illustrate the impact of these principles on the metaphysical level is to employ the many-worlds interpretation, which is the central postulate of quantum mechanics and which maintains that our universe is one of many possible universes, as each act of observation - each selection - causes the splitting of the world into that which was observed and that which was not. From that perspective, reality is revealed as a multiverse of all possible quantum results (cf. Byrne; Deutsch 294), which directly corresponds to Baudrillard's concepts of hyperreality and fractal subjects as co-existing potential configurations of mediated data that are actualized through the act of observation.

It is not surprising that in the domain of literature science fiction has been the first to react to the change of paradigm, as the new conditions directly interfere with its fundamental premises

\footnotetext{
"Superposition" is a state in which a particle can be in multiple states at once; "entanglement" refers to the coordination of the properties of two particles across space and time; and the "measurement problem" suggests that the act of observation alters the observed since the observer is always part of the system, interfering with it by the very act of measurement.
} 
and genre specifics - most notably with its focus on predominantly future-oriented, alternative ontological set-ups that are organized as to ensure cognitive dissonance. The reaction, generally attributed to the cyberpunk movement, was, however, more a matter of inevitability than intention. Once the subject of conventional SF extrapolation is a cybernetic machine which conceptually facilitates world-building through coding, the focus of SF exploration necessarily moves from the conventional distant futures to worlds which are - timewise - much closer to ours, and recognizable because they are built from the same building blocks and coded in the same way as our world. The thematic preoccupation with co-existing, familiar realities, none of which is more real than the next, brings cyberpunk into the conceptual vicinity of its mainstream contemporary - postmodernism. So much so, in fact, that the two find themselves on the same ontological plane, where "[c]yberpunk translates or transcodes postmodernist motifs from the level of form (verbal continuum, narrative strategies) to the level of content or 'world"' (McHale 1992, 246). The most obvious consequence is the much-theorized cyberpunk blurring of the dividing line between the genre and the mainstream (cf. McHale 1992, 236; Krevel 2012, 57).

In the subsequent decades this erosion of genre boundaries has expanded across the entire literary spectrum, meaning that cyberpunk was the herald of a broader change. Within the postmodern quantum paradigm, the prevailing definitions of science fiction - or any fiction - as an independent genre, the specifics of which profoundly differ from other instances of writing, can no longer apply. Take, for instance, the fundamental difference Darko Suvin charts between science fiction and (surely its closest relative) fantasy, namely that of possibility and impossibility. Suvin argues that science fiction produces worlds that are potentially possible because they fundamentally reference our empirical reality as its "dynamic transformation [...], not only a reflecting of but also on reality" $(2016,22)$. Fantasy, on the other hand, "creates a world where one or more all-important individual agents intimately interact with a spacetime not only radically different from the author's historical moment of social life but also, and primarily, denying history as socio-economic lawfulness" (2016, 404-5). A dialectics of this kind is utterly foreign to the principle of potentiality governing postmodern physics and metaphysics, according to which all realities a priori co-exist as a multiverse contained in the exponentially multiplying totality of mediated information. In the quantum paradigm, empirical and historical are purely arbitrary signs which acquire their meaning in relation to other signs that are part of the hyperreal system in which they participate.

Certainly the most literal examples of the last statement are the recent phenomena of fake news and alternative facts, which despite their alleged "untruthfulness" significantly interfere with the quotidian experiences of postmodern individuals. This brings us to the issues of what is true and what is real (and, more importantly, what is fiction) within the new paradigm, which also significantly affects the role, function and potential of literature in the current political, social and economic conditions. Once the notions of reality rely exclusively on media-transferred data, the fact that literature is a medium endows it with a reality-building potential. In other words, since before the realization in hyperreality all information has the same worth, "literary" data have the same potential for the creation of hyperreality as any other data. With that, the notions of realness and fictionality merge within the principle of potentiality, which in the event of its actualization as hyperreality produces the truth. It is along these lines that we can understand Landon's assessment that "the real message of cyberpunk was that of inevitability - not what the future might hold, but the inevitable hold of the present over the future - what the future could not fail to be" $(1992,239)$. Certainly the most notorious case in point is cyberspace, a coinage which seminal cyberpunk author William Gibson first used in his 1981 short-story "Burning 
Chrome" as a novum resulting from the extrapolative combination of computer technology of the late 1970s and the immersive effects of the early arcade games (Jones 2011). ${ }^{2}$ Not only has the word cyberspace become part of our everyday vocabulary (with much the same meaning of computer-enabled virtual reality), what it usually refers to - i.e. the internet - conceptually and structurally matches Gibson's invention. ${ }^{3}$

With the processing speed of computers increasing at a double exponential rate (Kurzweil 2006, 40-41), the ensuing acceleration of the manifestation of data on the experiential level inexorably decreases the distance between the future imagined and the present experienced, ideally by the same factor. If in the 1980s cyberpunk extrapolations charted a future that could not fail to be, two decades later the most prominent herald of that future, William Gibson, has repeatedly asserted in interviews that in the new millennium reality changes with a rapidity that prevents extrapolation of the present into a specific future. "Fully imagined cultural futures were the luxury of another day, one in which 'now' was of some greater duration. For us, of course, things can change so abruptly, so violently, so profoundly, that futures like our grandparents' have insufficient 'now' to stand on. We have no future because our present is too volatile" (Gibson 2004, 57), ruminates Hubertus Bigend, the central figure of Gibson's 2000s Bigend trilogy placed - accordingly - in the familiar settings of the post-9/11 reality. Tangible and recognizable as these settings are, they simultaneously emanate a distinctive SF feel - these worlds are cognitively dissonant (cf. Hollinger 2006; Tomberg 2013). It is as if in the first decade of the 2000 s the distance between the future and present not only disappeared, but that the future at that point had, in fact, all but colonised the present.

The shift of temporal focus in Gibson's works has indeed been largely attributed to the collapse of futurity upon the present in the techno-cultural societies of post-industrial capitalism. In his awardwinning study of Gibson's Bigend trilogy, Jaak Tomberg argues that the "cognitively dissonant pace of change in contemporary technocultural society" (Tomberg 2013, 264-65) renders imagining of ontologically different futures impossible. Veronica Hollinger similarly observes that in the societies of post-industrial capitalism the future no longer seems "a site of meaningful difference" $(2006,453)$, and the present, due to its totalizing spatial multiplicity, gains an estranging quality $(2006,465)$. Within the ontological framework of the current phase of postmodernity, governed by potentiality and corroborated by the latest developments in science, the shift of extrapolation from the temporal to the spatial axis initiated by cyberpunk indeed seems inevitable, making Gibson's 2000s "science-fiction realism" (Hollinger 2006, 460) paradigmatic of the development of science fiction in the new millennium (Jameson 2005, 392). And since within that framework any literary treatment of reality a priori produces a hyperreal potentiality of the present that is at once familiar and estranging, the convergence of the speculative and the mimetic might indeed prove to be the dominant mode of contemporary literary production in general.

This, and the fact that within such a set-up literature of any kind can no longer be associated with fiction(ality), brings us to the main concerns addressed in this issue of ELOPE: What is science fiction today? Is it a distinctive, independent genre, a speculative subgenre, a stylistic

The invention of the term has also been attributed to Vernor Vinge. As both used it at about the same time, it is unclear who had come up with it first. Given Gibson's popularity, however, the entering of the word into general vocabulary was most probably prompted by his usage.

3 Developments in the fields of genetics, robotics and nanotechnology from the 1990s onward have, in fact, in some way or other rendered a number of cognitively estranging nova from Gibson's 1980s Sprawl trilogy either literally or conceptually concrete. For a more detailed treatment see Krevel 2014. 
feature, or perhaps a mere marketing category? What is its relation to the present moment? What sort of impact can it have, what role can it play?

With regard to their main accent, the essays in this collection are organized into three largely provisional and permeable thematic clusters. Given that all the authors more or less explicitly acknowledge the waning of genre boundaries - and indeed all other boundaries - in their treatment of the various issues arising from the production of contemporary speculative and science fiction, the first section delves into the problematics of genre. The second cluster is dedicated to issues which are closely related to genre indeterminacy, namely the re-definition of the connection between (SF) speculation and experiential reality, as well as the possible repercussions of this re-definition. In the last part, the implications of the shift of extrapolative and speculative focus from the temporal to the spatial axis are explored, ultimately connecting the sprawling multiverses of narrative speculation across the mediascape to the current political and economic realities, as well as to the increasing permeability and arbitrariness of genre boundaries.

The issues arising with regard to the status of science fiction as a genre in the present day and age are the focus of Michelle Gadpaille's analysis of Margaret Atwood's 2006 short story “Three Novels I Won't Write Soon". Analysing the content from the perspective of existing definitions of the various speculative modes of writing, and Atwood's own engagement with science fiction, Gadpaille identifies features of science fiction, speculative fiction and climate fiction. These, however, despite their fundamentally speculative nature, fail to solidify into a genre or even a combination thereof due to the utter indeterminacy of the discourse they appear within. Examining stylistic idiosyncrasies, Gadpaille aligns Atwood's narrative with the discourse circulating within the spheres of contemporary ecotainment and science writing, where the speculative motifs that Gadpaille identifies on the level of content are prominently featured. From that perspective, Atwood's story is not only indicative of the permeability and arbitrariness of genre boundaries, but also of the boundaries between the various strata of contemporary cultural discourse in general.

The crossing of boundaries - between genre, media and realities - also underlies Victor Kennedy's examination of cartoon physics from the perspective of quantum mechanics and relativity theory. Cartoon physics is central in cartoons that parody contemporary science and its apostles in a way not unfamiliar to some earlier instances of science fiction. Moreover, since the medium of animation facilitates the inclusion of nova in much the same way as the written one, these cartoons produce the effect of cognitive estrangement typical of science fiction writing. In his analysis of the Road Runner series Kennedy shows that the seeming paradoxes of the cartoon physics employed do, in fact, conform to the principles of the measurement problem, tidal effect and superposition. As such their paradoxicality now becomes potentiality, and their satire a means of normalizing the nova in a world that is a novum in itself.

The potential of science fiction to interfere with existing realities in terms of greater equality and social justice by providing nova is explored and validated in Anamarija Šporčičs analysis of the relevance of science fiction to non-binary and genderqueer readers. The overview of existing SF challenges to the established notions of gender reveals a scarce and largely conventional treatment of gender issues until the 1970s, when, on the wings of second wave feminism and other civil rights movements, fictional explorations of the non-binary alternatives were (slightly) on the rise. Another incentive was provided by queer and performativity theories in the 1990s, as well as the transhumanist movement, resulting in works which translate the decisively abstract premises of these theories into various constellations of post-gender worlds. Because these worlds are essentially anchored in the same social and cultural conditions as their theoretical counterparts - 
and, indeed, all the other nova that shape our social and cultural realities - they may serve as a point of reference for being in the world not only to non-binary and genderqueer readers but to fractalized and quantized identities in general.

An instance of such a world is Ian M. Banks' Culture civilization, featured in his Culture series. In Antonia Leach's study of The Player of Games, Excession and "The State of the Art" from this series, gender issues are addressed within a broader context of posthuman worlds, focusing primarily on the questions of corporeality and embodiment, consciousness and sentience. Banks envisions a society in which artificial intelligence is the species in control. This position, however, is not the result of a mechanical invention but of the inevitable evolutionary progress. This progress not only entails a radically higher degree of intelligence but also a moral position which corresponds to the ontological foundation of the new species: namely that of potentiality and selection. The divide between the human and posthuman is no longer a matter of essentialism but of choice. The body is rendered optional and the essence of selfhood moves to the mind, which here differs from that of the dominant species in degree, not in kind. In Banks' posthuman universe, Leach concludes, personhood is a matter of sentience, not biological provenience.

That the makings of such a world are already well underway is bluntly exposed in Heather Duncan's exploration of the notion of life after death in three contemporary genre narratives: a Reddit "creepypasta", an episode of TV series Black Mirror, and Paul La Farge's novel The Night Ocean. Regardless of the medium in which these narratives appear, Duncan shows, life after death is revealed as a narrative construction. In the age of smart machines, the notion of the agency of consciousness regardless of its embodiment is no longer a matter of continuity (i.e. afterlife), but the dominant mode of construction of the many selves that we embody in various ways. Identity is revealed as an assemblage of narratives, which construct the self through recognizable patterns, which can be reproduced indefinitely. And since pattern recognition, reproduction and dissemination describe the modus operandi of the dominant digital medium, narrative agency transcends biological constraints, and personhood is yet again revealed as a matter of sentience, and not humanness. The role of the speculative genre today, argues Duncan, is to provide the platform for the cognitive placement of the current state of affairs, where the borders between the media, genres, the real and the fictive, life and death, and the biological and non-biological are but narrative constructions - a matter of pattern rather than an essentiality.

A connection between the transgressions of genre borders, ideas of space, and current political and economic realities is further explored in the last two essays of this collection. Urša Vogrinc Javoršek examines Neil Gaiman's Neverwhere (1996), Iain Banks' Transition (2009) and China Miéville's The City \& the City (2009) from the perspective of their conceptions of space. Her analysis reveals an evolutionary pattern in the responses of science fiction and speculative writing to the advancing "postmodernization" of the notion of space. While Gaiman's parallel Londons are an instance of Foucault's heterotopia, Bank's novel structurally and conceptually establishes a Deleuzian rhizomatous multiverse. Miéville's two cities, occupying the same temporal and spatial location in The City \& the City, correspond to de Certeau's notion of absent space. Vogrinc Javoršek shows that the multiplication, coexistence and overlaying of spaces in these novels reflect the political, social and economic conditions at the time of their conception, and reveal their authors' leftist political agendas. Moreover, with the proliferation of parallel multiverses in these narratives, and the increasingly permeable, fluid and virtual nature of their borders, genre identity gradually dissolves into a multitude of coexisting genre potentialities which ultimately occupy the same temporal location of an all-embracing, familiar transnarrative now. 
The nature of this now is also scrutinized in Pablo Gómez Muñoz's analysis of the 2013 film Elysium from the perspective of the on-going reorganization of spaces - territorial and otherwise - and societies in the paradigm of global neoliberalism. Like Vogrinc Javoršek, Gómez Muñoz identifies the preoccupation with redefinition of borders and border-related issues as the predominant concern in cinematic SF production at the turn of the century and beyond. Based on geopolitical, border and globalization theories, Gómez Muñoz's essay charts the unequivocal parallels between the novel forms of borders and territories - the speculative novaas dictated by the socio-political and economic system in Elysium, and the on-going processes of the redefinition and reconstruction of the notion of borders in terms of their separation from the concepts of territory and sovereignty. These borders are superposed to serve the interests of global capital, and as such are revealed as dispersed, mobile and embodied. Elysium is therefore firmly anchored in the paradigm of now. So much so, in fact, that the solutions it offers in the form of a happy ending fall prey to the logic of the system the film allegedly criticizes. As such, Gómez Muñoz argues, the narrative of Elysium perpetuates rather than challenges the dominant neoliberal discourse.

Considering the fact that Elysium is a Hollywood all-star blockbuster, a phenomenon that relies precisely on the neoliberal dispersal, mobility and embodiment of borders in order to serve private economic interests, a different scenario could hardly be expected. But perhaps the solution lies in applying the very principle that facilitates the manipulation of borders in ways that strengthen and perpetuate the dominance of global capitalism, that is, the relativization of any boundaries inherent to the paradigm of postmodernity, to the very borders neoliberal capitalism establishes and normalizes. Ljubica Matek's review of Iva Polak's book Futuristic Worlds in Australian Aboriginal Fiction, which concludes this issue of ELOPE, provides a brief insight into an attempt to do just that.

The permeability, fluidity and arbitrariness of any boundaries within present political, economic and social conditions make the order in which the contributions are placed, as well as their distribution into individual clusters, necessarily a matter of my interpretation, based on the information that has formed my experiential horizon - my reality. As a whole, however, the essays in this collection encompass a totality of countless possible interpretations, a multiverse that, if anything, attests to the fact that as long as science fiction does, science fiction is. And even if at this particular point in space and time it may not be clear exactly what science fiction $i s$, as long as it is part of contemporary narratives it significantly affects the realities we find ourselves in, as well as those that exist as a potentiality - the ones which, in the old days were referred to as the future, the past, and fiction. It may very well turn out that the role of science fiction today, in any way, shape, or form, is to help us realize that those potential (other) worlds interfere with ours just as the past, the future and fiction determined the world before the apocalypse. In a situation where, as we speak, the herald of the apocalypse William Gibson is re-writing his last novel because the original version relied on the speculation that Donald Trump had won the election (Kean 2017), such a role for science fiction is a scenario devoutly to be wished.

\section{Acknowledgements}

The author acknowledges the financial support from the Slovenian Research Agency (research core funding No. P6-0265). 


\section{References}

Baudrillard, Jean. 2004. "Simulacra and Simulations." In Literary Theory: An Anthology, edited by Julie Rivkin and Michael Ryan, 365-77. Maiden: Blackwell.

—. 2011. Impossible Exchange. Translated by Chris Turner. London: Verso.

Byrne, Peter. 2008. "The Many Worlds of Hugh Everett.” Scientific American, October 21, 2008. https://www. scientificamerican.com/article/hugh-everett-biography/.

Deutsch, David. 2011. The Beginning of Infinity: Explanations that Transform the World. London: Allen Lane.

Gibson, William. 2003. Pattern Recognition. New York: Berkley Books.

Hollinger, Veronica. 2006. "Stories about the Future: From Patterns of Expectation to Pattern Recognition." Science Fiction Studies 33 (3): 452-72.

Jameson, Fredric. 2007. Archaeologies of the Future. The Desire Called Utopia and Other Science Fictions. London: Verso.

Jones, Thomas. 2011. “William Gibson: Beyond Cyberspace.” The Guardian, September 22, 2011. https:// www.theguardian.com/books/2011/sep/22/william-gibson-beyond-cyberspace.

Kean, Danuta. 2017. "New William Gibson Novel Set in a World Where Hillary Clinton Won.” The Guardian, April 26, 2017. https:/www.theguardian.com/books/2017/apr/26/new-william-gibson-novelworld-where-hillary-clinton-won-agency.

Kittler, Friedrich, Dorothea von Mücke, and Phillippe L. Similon. 1987. "Gramophone, Film, Typewriter." October 41: 101-18.

Krevel, Mojca. 2012. "Ghost Busting: The Role of Literary Cyberpunk in the Development of Fiction at the End of the Twentieth Century." Arbeiten aus Anglistik und Amerikanistik 37 (1): 49-67.

—. 2014. "'Back to the Future': Technological Singularity in Gibson's Sprawl Trilogy." B.A.S. British and American Studies XX: 27-36.

—. 2016. "Navzočnost v času: A Tale for the Time Being in postmoderna paradigma. Primerjalna književnost 39 (2): 173-90.

Kurzweil, Ray. 2006. The Singularity Is Near: When Humans Transcend Biology. London: Penguin Books.

Landon, Brooks. 1991. "Bet On It: Cyber/Video/Punk Performance." In Storming the Reality Studio. A Casebook of Cyberpunk and Postmodern Fiction, edited by Larry McCaffery, 238-44. Durham \& London: Duke University Press.

McHale, Brian. 1992. Constructing Postmodernism. London, New York: Routledge.

Shannon, Claude E., and Warren Weaver. 1949. The Mathematical Theory of Communication. Urbana: University of Illinois Press.

Suvin, Darko. 2016. Metamorphoses of Science Fiction. On the Poetics and History of a Literary Genre. Bern: Peter Lang.

Tomberg, Jaak. 2013. "On the 'Double Vision' of Realism and SF Estrangement in William Gibson's Bigend Trilogy." Science Fiction Studies 40 (2): 263-85. https://doi.org/10.5621/sciefictstud.40.2.0263. 